Journal of NELTA Gandaki (JoNG)

(A peer reviewed Open Access Research Journal)

ISSN: 2676-1041 [Print] E-ISSN 2822-1559 [Online]

Vol. IV Issue (1-2) November, 2021, pp. 109-118

eJournal site: www.nelta.org.np/page/gandaki

\title{
English Medium Instruction in Multilingual Classroom of Community Schools of
}

Nepal

Article History:

Submitted 22 June, 2021

Reviewed 30 September 2021

Accepted 30 October 2021

Corresponding Author:

Debraj Karki

Email:

karkidr2016@gmail.com

Article DOI:

https://doi.org/10.3126/jong.v4i1-2.42650

\section{Copyright information:}

Copyright 2021 Author/s and Nepal English Language Teachers' Association, Gandaki Province

This work is licensed under a Creative Commons Attribution- Non

\section{Commercial}

4.0 International License

\section{(CC)}

Publisher

Nepal English Language Teachers'

Association Gandaki Province, Pokhara, Nepal

Email: neltagandaki2018@gmail.com URL.:www.nelta.org.np/page/gandaki

Debraj Karki

\section{Abstract}

Multilingualism and multilingual classroom are the reality of language education in Nepal. Teaching in multilingual classroom is both fascinating and challenging for teachers. The article aims at exploring how the monolingual ideology over English language teaching has created a gap between the linguistic capital of learners and the authoritative pedagogical practices of teachers. Taking case of a community school in Lalitpur district, I investigate the practices of teaching English to multilingual learners in a community school and explore pertinent issues of monolingual practices in a multilingual classroom. I draw data from informal telephonic talk to a subject teacher selecting purposively and observe the instructional practices in the linguistically diversified classroom. The article makes two major claims regarding the excessive use of monolingual teaching kills the inner potentialities of learners and suggests embodying multilingual pedagogy to foster learners' epistemic growth in a natural and comfortable environment. The teachers should transform themselves to bring change and innovation in course of their pedagogical journey. Such kind of innovation is only feasible if teachers construct and reconstruct their pedagogical assumptions as of the need of learners. So that diversified learners are addressed properly in their knowledge gaining content. It further informs that immense investigation on language classrooms to bring a paradigm shift in English

language education is essential in the days to go.

Keywords: monolingual ideology, multilingual classroom, phenomenological inquiry, multilingual pedagogy, thematic network analysis 


\section{Introduction}

Nepal is a "multi- ethnic, multi - lingual, multi - religious, multi - cultural (Government of Nepal, 2015, Article, 3) nation with common aspirations of people living in diversified society. People have been living with mutual tolerance and understanding among each other which show the respect and support regarding each other treasures. According to the 2011 census report, 123 languages are spoken as 'mother tongue' by 125 ethnic groups in Nepal (Central Bureau Statistics [CBS], 2012). These languages are genetically affiliated with four language families: indo - European, Sino - Tibetan, Austro - Asiatic and Dravidian. Among them, indo European language family is the largest language group in Nepal in term of the number of speakers and Sino-Tibetan is the largest language family based on the number of languages. Similarly, according to (CBS, 2012), there are $44.6 \%$ people who speak Nepali as their mother tongue and $11.7 \%$ speak Maithili Bhojpuri 5.98\%, Tharu 5.77\%, Tamang 5.11\%, Newar 3.2\%, Bajika $2.99 \%$ ,Magar 2.98\%, Doteli, 2.97\% and 2.61Urdu . Among them, 19 languages have more than 100,000 and in our country. This report suggests that Nepal is a multilingual country and the school classroom is a multilingual classroom as well.

Multilingualism has been a natural asset of our community. Almost all societies are multilingual and multicultural and it has been the fluidity of the $21^{\text {st }}$ century. A community becomes multilingual due to the existence of different types of languages and their aim. Cenoz and Gorter (2010) mention that a community is multilingual from its dominant national language, classical languages, regional languages, immigrants' languages and foreign languages (p. 5). All these types of languages have different pertinent aims which are inevitable to adjust an individual in his dynamic and evolving life. Therefore, present multilingual education has been as a complex phenomenon which highlights the interaction of linguistic, sociolinguistic and education variables and such kind of multilingualism and linguistics diversity naturally creates multilingual classroom in terms of language, culture, race and ethnicity.

In such multilingual classroom, the policy of language teaching is still guided by monolingual pedagogy in the context of Nepal. Due to the monolingual language policy, other language speakers are facing an increasing pressure of language shift. English language has been as a lingua - Franca after Nepali and the language of business, tourism and for abroad. There are $0.01 \%$ speak English as their mother tongue which comes in $76^{\text {th }}$ position in rank. It has the status of a foreign language in the teaching and learning process. It has been taught as a compulsory subject from grade 1 to bachelor level and an optional subject from grade 9 to post graduate level. The role of English in education seems to be significant and its use is compared to be one of the quality parameters in the educational delivery and achievement. It is mostly found in the private institution that English has been as a hegemonic language of instruction. It has been the medium of instruction in private, public, schools, colleagues and even universities. However, there is still blur on how to improve the quality of education especially language teaching and introduce English in multilingual context of Nepal. Whether it should be used as compulsory subject or optional, whether it should be used as an appropriate medium of instruction at the primary level or there should be used mother tongue as the medium of instruction. Although The Constitution of Nepal (2015) guarantees 
the right of communities to protect, preserve and promote minority language and states that citizens will not be discriminated based on their linguistic, ethnic, political and religious background, the rhetoric of multilingualism has seldom been experienced by the people in education, government office and other public sphere cited in Phyak (2019). If English is used both as compulsory subject and medium of instruction to teach content - related subject, how we consider the spaces of indigenous languages which is the source of knowledge in multilingual classroom. Similarly, if indigenous languages are adopted as the medium of instruction, how can we select and manage the languages among many in the classroom and how can we assimilate with the global importance of English in the present complex world. Such kind of contradictory notions raise the issue of investigation regarding English language teaching. Existence literature suggests that English language teaching in terms of monolingual policy does not address the prior experience and knowledge of learners. Neither, it creates a productive environment in the multilingual classroom. Instead, it has been monotonous, boring and tedious which we metaphorically called bhalulai puran in multilingual classroom. Therefore, it is essential to investigate role of the English language in multilingual classroom and the position of learners' repertoire that is their indigenous linguistic capital as well as the perception and understandings of multilingual learners regarding the learning and achievement of monolingual pedagogy.

\section{Theoretical Underpinning}

Multilingualism refers to the possession of two or more languages by speakers, irrespective of the language proficiency level. It is based on fundamental human ability to be able to communicate in several languages in the real social - cultural context. Franceschini (2011) states multilingualism is widely used to describe the various forms of social, institutional and individual ways that we go about using more than one language. The current social interest in multilingualism is a part of a change in perspectives. The diffusion of the notion multilingualism with an ongoing change in society is due to an increased sensibility toward diversity and increased waves of migration. In such fluid, dynamic and mixing nature of society, multilingualism should be seriously embedded in the part of language education. European Union (EU) has set the goal of promoting two languages in addition to first language and aiming at developing trilingual citizens in future.

The multilingual context of the school and multilingual classroom has been hot topic of discussion in present day education. The existence reality of classroom is multilingual. So the pursuit of teaching learning activities in the classroom should be guided by the strategies for responding to the linguistic and cultural diversity of school. In this context, Sierens and Amrmaet (2013) suggest three strategies to implement in a multilingual classroom: a constructive language policy in which students' home language is taken as an asset and part of the multilingual repertoire. For that school can implement language immersion program. If the school imposes strict linguistic rule, it gives a negative impact to the wellbeing of young learners. Similarly, a language awareness raising policy can also be implemented in the classroom. This policy focuses on the interaction between students themselves and among students and teachers as well. It creates positive vibes to all the indigenous languages of leaners. They feel their existence of identity in 
school. The third policy is the functional multilingual learning which asserts that student's mother tongue is the stepping stone to the acquisition of second language and learning of new content. It functions as didactic capital to personal and educational success of learners. The policy makers should consider such strategies seriously. But monolingual ideology guides the behaviors of a particular community and tied to the question of identity and power (Cited in Christiansen, Guzman \& Mora - Pablo, 2017). Educational stakeholders strongly force to impose monolingual policy in school education due to the influence of politics and power and students' home language is devalued and ignored from so-called structured school education. But it is essential to focus on collective representation of linguistic attitude of the community (Linddicoat, \& Leech, 2015). Ignoring learners' knowledge capital is against learning pedagogy and it does not enhance the quality of learning. Cognitive development is deeply rooted to the prior knowledge of learners. So, it should be taken as the centrality of classroom teaching. May (2013) talks on the multilingual turn' in language teaching with the introduction of pluralistic approach. The approach indicates to imposing multiple languages in diversified classroom. He adds that there is co - existence of multiple languages in society and it is essential to acknowledge individual's multilingual repertoire in language classroom. When multilingual repertoire is addressed in the classroom, learners possess multi-competence (Cook, 1992), which is the type of super system, makes the knowledge of multiple languages in one mind. For the sustainable development of multicompetence, holistic approach (Cenoz \& Gorter, 2011) should be implemented in the classroom. The teacher applies codeswitching, translanguaging, and codemeshing in teaching-learning activities. Holistic approach coordinates among language teachers to use integrated language curriculum which highlights the relationship between the languages and can potentially develops learners' language awareness (as cited in Cenoz \& Gorter, 2011). Such kind of strategies really encourages rethinking and conceptualizing the instructional strategies in multilingual classroom.

It is, however, found that language teachers have been practicing monolingual strategies, particularly lecture and explanation, in English classroom. They are doing very hard work to explain the content through English language. Students remain almost silent or speaking agreeable words to the teachers. Such kind of traditional and monolingual strategies in English classroom raised some questions in my mind. Why are language teachers ignoring the linguistic and cultural capital of learners? Can learners achieve competence through lecture and explanation in English language? How do multilingual learners learn English? What are the pertinent issues or challenges of monolingual strategies in multilingual classroom? How can we overcome the issues or challenges? Such bombarding questions approached me to explore the multilingual classroom seriously.

\section{Methods}

This study was based on the qualitative phenomenological design which adheres that appearances are opposed to reality. Perception, thought, memory, imagination, emotion, desire and volition to bodily awareness are linked to the lived experiences of participants. It studies the structure of various types of experience and intentionality from first person point of view. Phenomenologists are concerned with understanding social and psychological phenomena from the perspectives of people involved (Groenewald, 
2004, p. 44). It focuses on lived human experiences and practices with the issue that is researched. Similarly, the central concern of phenomenologists is to identify the understanding of life which can emerge from an individuals' experience (Whitehead, 2002). Considering above standpoint, i also used phenomenological research design to explore the lived experiences of secondary level English teacher of Lalitpur district.The participant of my study was a secondary level English teacher of Lalitpur district. He has been teaching in a community school for fifteen years. He has strong experience in teaching English. He believes that English language should be taught through English for the clarification of content and succession in examination. He further adds that English language competency is the need of time, so we have to engage learners to practice on it. He claims that the more English, the better. He has been also appointed as an English language trainer in Lalitpur district Metropolitan city.

As a researcher, I implemented some systematic procedures to collect the data from the primary sources. First, I prepared the required and proposed tools for the study. Then, I established the rapport with the concerned authorities and the teachers. I briefly reported the purposes and the terms for confidentiality. Keeping the goals in mind, first, class of the teacher was observed (ten classes) and recorded via audio device and also recorded as a field notes in a diary. Then, after transcribing the data from the classroom observation and reading it in detail, I did informal telephonic interview with the teacher to explore their experiences of using students' home languages in the classrooms and their agency for their professional development.

As per the nature of the study, I used qualitative approach to data analysis in general including transcribing, editing, summarizing, organizing, categorizing, deriving conclusions (Attride-Sterling, 2001). In doing so, thematic network analysis technique was adopted to generate the global themes from basic and organizing themes by linking with existing relevant literature. First, I described my own experience with the object of study in order to identify personal judgments and prejudices so that they did not affect the process of analysis. Secondly, I listed each of the relevant quotes of the studied topic and gave them equal value with regard to the expressions of the group. Thirdly, I grouped the relevant topics into units of meaning. Fourthly, I wrote the textual description using "ad verbatim" quotations. Fifthly, I wrote the structural description. And finally, according to the textual and structural analysis, I identified the essence of the phenomenon.

\section{Results and Discussion}

\section{English as a Dominant Medium of Instruction}

My class observation indicates that English has the dominant role in the classroom. The teacher (my participant) started the lesson in English and continues it through English. He does not care how multilingual learners learn it. The class observation showed that the teacher is mostly concerned on completing the course but he seems reluctant whether learners are engaging with him or not. Such kind of one way instruction is against the multilingual and multicultural policy, The Constitution of Nepal (2015). It indicates that language teachers are not aware to the multilingual policy of government. One of the short excerpts from my class observation is mentioned as for example: 
T: do students do their work themselves? (Into yes / no question)

Ss: do students do their work themselves?

T: very good... and last question mark... here, 'do' as the main verb... and it is V1 form... you have to use do first and same V1... Do V1 form ma xa tesaile helping verb do use garne ra finally write question mark ['do' is in V1 form. So helping verb 'do' is used and question mark at the end]. Ss': ok sir.

The excerpt from class observation informs that there is the dominant role of English language in course of explanation and students have very few responses on it. They have been as passive listener and just listen what the teacher is explaining the topic. Such kind of monolingual ideological influence in the classroom makes me discuss on the participant. The participants stated: English is the language to learn and I always focus on the development of English language competency in the classroom. $\mathrm{He}$ further added that: the more we use English in the classroom; the weak learners are also compelled to learn English. I, from the participant response, came to the point that he is entirely guided the dominant role of English language. it ignores the ignores the constructive language policy (Sierens \& Amrmaet, 2013) in which students home language is taken as the main interactive tool for classroom discussion and internalization of knowledge. Similarly it equally ignores language awareness raising policy and the most influential the functional multilingual learning policy(I). The language awareness raising policy focuses on the interaction between students themselves and between students and teachers in their home language. This policy creates positive attitude towards all languages. Similarly, functional multilingual learning policy suggests schools to use multilingual repertoires of children and adolescents to ring the changes of knowledge acquisition. Such kind of recent research findings have been entirely ignored in the classroom and the prescriptive monolingual notion has been implemented in the classroom. Such kind of pedagogy becomes worthless in diversified and multilingual classroom.

\section{Ignorance of Learners' Prior Knowledge}

Learners' prior knowledge is considered as significant foundation of learning. It makes learners feel free and develop confident in classroom activities. However, most of the language teachers couldn't address such underlying potentialities of learners and they merely teach the assigned content in their curriculum. Many of them are not aware in this matter and some of them do not care on it even they know it is significant in the course of teaching learning activities. Learners are supposed as an empty vessel in which teachers begin to fill the content knowledge prescribed in curriculum. This is very traditional sort of notion, which totally ignore learners' linguistic repertoire. My observation of English class and the mentioned Vignett reflects that there was authoritative role played by teachers. Learners participation in the classroom is merely as 'yes man' what the teacher was confirming in his teaching. I did not find whether learners were trying to present their reflection in their learning nor the teacher was creating such interactive and collaborative environment in the classroom. My observation found the following role between teacher and learners: 


\section{Classroom vignette}

T... it also describes the number of boys and girls in different academic years...2011..2012..2013...2014...and 2015...of this year the number of students have been presented...this color refers to the number of boys and number of girls in thousand...here is $100 \ldots 200 \ldots 300 \ldots 400 \ldots 500 \ldots$ so that's way here is mentioned... so it is a chart or bar diagram... aslai $k$ bhanxa re feri bhanusta [tell me, what is it called]?

Ss : chart or bar diagram.

T: asto chart abam bar diagram lai three column ma lekhaunu parxa ... bujau students asko barema [this chart and bar diagram are kept in three column. Do you understand students?].

Ss : bujau sir [yes sir].

The small instance of classroom vignette suggests that there is strong domination and huge describes the diagram in simple language. He speaks in Nepali language to confirm the explanation. In informal talk, the participant said: I speak Nepali language to confirm whether learners are with me or not. He added that Nepali is the contact language to all of them. So I use it. It indicates that teachers do not dare to use students' first language or prior knowledge of home language in the classroom. This notion of teachers' is the traditional method of teaching. It ignores the multilingual repertoire of learners. Similarly, it prevents the multi - competence, (Cook, 1991) of learners. Cook argues that learners possess special super system which makes them acquire knowledge of multiple languages in one mind. Similarly, the one way explanation of teacher against learning pedagogy (Linddicoat \& Leech, 2015) and it does not enhance the quality of learning. Cognitive development is deeply rooted to the prior knowledge of learners but such rich knowledge capital is entirely ignored by teachers which are against child rights of learning. Similarly, such kind of ignorance of learners' is just like the futile and meaningless teaching in such competitive $21^{\text {st }}$ century teaching. Another short instance of codeswitching in the classroom teaching:

$T$...ho first paragraph ma tapain le ke lakhne bhanda kheri [yes start your first paragraph] ... the above chart displays / illustrates...lu yo slide ma hernus ta [let's see the slide]...astai garnu parxa [do like this]... second paragraph ma chai what do you write [in second paragraph]...you have to give detailed information what is the text about...tyo text ko ko barema xa tapaiharule detaile description ma dina saknu pardaxa [give detailed description of the given text]...la tya hrenus la kasari diyako xa [now lets' see what has been given in the text]...now in third part... third paragraph ma chai concluding remarks and tapainharuko idea pani dina saknu hunxa [here you have to write concluding remarks with your personal ideas]...now let's see the concluding paragraph...it refers to the overall view of chart or graph...asari hamile chart athawa graph lai interpretation garnu pardaxa [in this way, we have to interpret chart or graph]...clear idea ayo student [do you understand?].

SS: ) ayo sir [ yes sir].

$T$ : asari garna sakinxa? [Can you do like this?]

Ss : sakinxa sir [yes sir] 
This another conversational chunk illuminates that learners have been immensely controlled in learning process and they have been just as the dormant listeners in the classroom. It is against learning rights and does not develop confidence among learners. It also clarifies that when teachers explain the content mostly in target language and little bit in learners' language, they confidently believe that learners understand everything in the classroom. This is very primitive and prescriptive notion of pedagogy. How learners foster their creative knowledge in such authoritative classroom? It is the big issue for studies in the diversified and competitive time.

\section{Need of Multilingual Strategies in the Diversified Classroom}

Multilingual strategies are the fundamental pre- requisite of diversified classroom. Such strategies engage learners actively in the classroom. They focus on learner autonomy from academically and socially. Academic autonomy creates collaborative and interactive environment in the classroom. Similarly, social autonomy transforms their classroom cognition in their community. However, such creative and constructive learning strategies have been entirely ignored in the classroom and ample use of lecture and explanation are found. In this context, the participant in informal discussion states: I cannot use learners' first language. I am unknown about it and there are more than a dozen languages in the classroom. Using such more language diverts the main objectives of lesson. Such propositions of participant reflect the dominant role of English langue in the classroom. Similarly, the teacher is unknown to the effectiveness of multilingual strategies in the classroom. Sirens and Amrmaet (2013) suggest three most constructive strategies in the multilingual classroom: constructive language strategies, language awareness strategies and functional multilingual strategies. These strategies create considerable collaborative and interactive engagement in learning activities. But such learner - centered strategies have been entirely ignored and traditional techniques: lecture, explanation and translation have been used. They make learners tedious and less interactive in the classroom. My participant in telephonic interview said:

I teach most of the content in English and when detailed explanation is necessary I use Nepali language. In such mixed language my almost $80 \%$ students do the assigned task. They easily solve language activities in the book. Even learners have many other mother tongues; their classroom contact language is Nepali. So I use Nepali language which is comprehensible for all of them. Similarly, my SEE result is excellent in terms of such pedagogy.

The excerpt highlights to complete the content given in the textbook and make learners score high in the exam. It does not emphasize the increment of learners' competencies. The fact is that high scoring can be achieved by route learning. It is not the main competency of English language teaching in the classroom. Does the prescribed knowledge of textbook solve the social issues of learners? Or is the classroom not a proper venue to discuss and learn the social issues of learners? Are there other institutions to learn for solving the social issues of learners? School is, no doubt, the one and only institution by which learners are able to cope with any sorts of individual and social issues in their life. In this context, May (2013) highlights pluralistic approach in language classroom. He states that our society has multiple languages and it is essential to use languages in the classroom. When classroom is assumed as mini-society and used 
multiple languages in learning, it develops multi - competence in learners and they are able to solve any sorts of challenges they face in the classroom.

\section{Conclusion and Implications}

The findings imply that English has been dominant language in the classroom. Teachers deliver the lesson through English even some Nepali expressions are used in the teaching. It indicates that English plays hegemonic and dominant role in the classroom. It ignores the prior knowledge of learners. It is the most significant part of teaching - learning activities. In order to expose such linguistic and cultural repertoire of learners, context sensitive multilingual strategies: constructive language strategies, language awareness strategies and the functional multilingual strategies should be used.

The study further suggests that there has been paradigm shift in course of English language teaching. The monolingual ideological notion of language teaching has been shifted to multilingual pedagogy in the diversified classroom. Therefore, further research should explore to use learners" prior knowledge in the classroom. Similarly, the study informs researchers to uncover and apply multilingual strategies in the diversified classroom. I have collected data from single participant, so extended investigation can be conducted by engaging many participants in the same issue as well. There have been several issues by monolingual pedagogy such as being learners as yes - man type of product and being unable to cope with any sorts of challenges found in their real life situation. Such type of traditional based teaching does not address the linguistic capital of learners, nor does such pedagogy make learners get adjustment in such fluid, and dynamic and evolving formation of society. Therefore, the study implies to investigate and recent trend of English language teaching and it further points out to raise strong voice against the dominant sorts of traditional based teaching.

\section{References}

Anton, M. M. (1996).Using ethnographic techniques in classroom observation: a study of success in a foreign language class. Foreign Language Annals, 29(4), 551-561. https://doi.org/10.1111/j.1944-9720.1996. tb01266.x

Attride-Sterling, J. (2001). Thematic networks: An analytic tool for qualitative research. Qualitative Research, 1(3), 385-405. https://doi.org/10.1177/146879410100100307

Braun,V., \& Clarke, V. (2006). Using thematic analysis in psychology. Qualitative Research in Psychology,3(2), 77- 101. http://dx.doi.org/10.1191/1478088706pq0630oa

Cenoz, J., \& Gorter, D. (2010). The diversity of multilingualism in education. International Journal of the Sociology of Language, 205, 37-53. https://doi.org/ 10.1515/IJSL.2010.038

Cenoz, J., \& Gorter, D. (2011).A holistic approach to multilingual education: Introduction. The Modern Language Journal, 95, iii. https://doi.org/10.1111/j.1540-4781.2011.01204.x0026-7902/11/339-343 Central Bureau of Statistics. (2012). National population and housing census.2011: National report. Author.

Chrustiansen, M. S., Guzman, N. P., \& Mora - Pablo, I. (2017). You know English, so why don’t you teach? Language ideologies and returnees becoming English language teachers in Mexico. International Multilingual Research Journal, 12(2), 80- 95. https://doi.org/10.1080/19313152.20171401446 
Franceschini, R. (2011). Multilingualism and multicompetence: A conceptual view. The Modern Language Journal, 95 iii, 344- 355. https://doi.org/10.1111/j.1540-4781.2011.01202.x0026 -7902/11

Government of Nepal (2015). Constitution of Nepal. Author.

Groenewald, T. (2004). A phenomenological research design illustrated. International Journal of Qualitative Methods, 3(1), 42- 55. http://doi: org/10.1177/160940690400300104

Liddicoat, A.,J. \& Leeech, K., T. (2015). Multilingual education: The role of language ideologies and attitudes. Current Issues in Language Planning, 16(1-2), 1 -7. _http://dx.doi.org/10.1080/14664208 .2015 .995753

May, S. (Ed.). (2013). The multilingual turn: Implications for SLA, TESOL, and bilingual education. Routledge. https://doi.org/10.4324/9780203113493

Phyak, P., \& Ojha. L., P. (2019). Language education policy and inequalities of multilingualism in Nepal. In A. Kirkpatric \& A. J. Liddicoat (Eds.), The Routledge international handbook of language education policy in Asia (pp.341-354). Routledge. https:/www.routledgehandbooks.com/ doi/10.4324/9781315666235-24

Sierens, S., \& Amermaet, P, V. (2013). Language diversity in education: Evolving from multilingual education to functional multilingual learning. In D. Little, C. Leung \& P. V. Avermaet (Eds.), Managing diversity in education: Languages, polices, pedagogies (pp. 204- 222). Multilingual Matters. https://doi.org/10.21832/9781783090815-014

Watson - Gegeo, K., A. (1988). Ethnography in ESL: Defining the essentials. TESOL QUARTERLY, 22(4), 575- 592. https://doi.org/10.2307/3587257

Whitehead, D. (2002). The academic writing experiences of a group of student nurses: A phenomenological study. Journal of Advanced Nursing, 38(5), 498 -506.

Mr Debraj Karki is a lecturer at Bright Future College, Satdobatio, Lalitpur. He has been teaching at B.Ed program for more than fifteen years. To his credit, a number of research articles have been published at different national peer reviewed journals. He has presented several papers at national and international ELT forum. His research area is on multilingualism, critical pedagogy and language policy and planning. 